\title{
Management of Pregnancy Complicated by Hypertrophic Obstructive Cardiomyopathy*
}

\author{
GILLIAN M. TURNER, M.B., B.S., M.R.C.O.G. ; CELIA M. OAKLEY, M.D., M.R.C.P. \\ H. G. DIXON, PH.D., F.R.C.P.ED., F.R.C.O.G.
}

Brit. med. F., 1968, 4, 281-284

\begin{abstract}
Summary : We report our experiences with nine women $\checkmark$ suffering from hypertrophic obstructive cardiomyopathy who between them had 13 pregnancies, 10 of which were directly managed by us. Though at first we felt that the theoretical hazards of vaginal delivery indicated elective caesarean section, experience has convinced us that in the absence of an obstetrical contraindication these patients may be delivered vaginally provided a betaadrenergic blocking drug is administered during pregnancy and especially during labour, ergometrine is given at the end of the second stage, adequate supplies of cross-matched blood are available, and prophylaxis against infective endocarditis is administered. We have found no evidence of any adverse effects of either propranolol or pronethalol on the foetus.
\end{abstract}

\section{Introduction}

During the past 10 years it has become apparent that hypertrophic obstructive cardiomyopathy is not a rare disease but that it has many disguises. A variety of clinical presentations and abnormal haemodynamics are now well recognized (Braunwald et al., 1964 ; Cohen et al., 1964 ; Burchell, 1966 ; Ross et al., 1966 ; Rackley et al., 1966), but the natural history is still not fully known.

Although the highest incidence of the disease is in young adults, its influence on the course of pregnancy has not yet been described. We report our experience of 13 pregnancies which occurred among nine of the over 80 patients with hypertrophic obstructive cardiomyopathy who have been investigated and treated at Hammersmith Hospital during the past 10 years.

\section{Differential Diagnosis}

The differential diagnosis is from aortic stenosis, ventricular septal defect, mitral regurgitation, and, most important of all, from normality. The physical signs correlate well with the haemodynamic abnormality in any particular patient. When left ventricular outflow obstruction is most important the signs may mimic aontic stenosis, ventricular septal defect, or mitral regurgitation. When there is mainly obstruction to the left ventricular filling the symptoms and signs mimic mitral stenosis, or the symptoms may even be thought to be neurotic in origin. Differentiation from innocent murmurs in healthy young people can be difficult, especially during pregnancy, when loud ejection murmurs and added sounds are so common (Cutforth and MacDonald, 1966). Sudden death may be the first sign of the disorder, but many patients with apparently similar haemodynamics remain asymptomatic and even athletic for years. A family history is not uncommon and was encountered in about one-third of our patients.

* From the Institute of Obstetrics and Gynaecology, Hammersmith Hospital, and the Department of Cardiology, Royal Postgraduate Medical School, London W.12.

\section{Management of Pregnancy}

The labile abnormality of left ventricular function, which is the hallmark of this heart disease, will be considered in the light of the physiological cardiovascular adjustments which take place during pregnancy. The modifications which can be brought about by external influences also have to be weighed carefully when deciding on the best management of pregnancy and delivery in women with hypertrophic obstructive cardiomyopathy.

In a patient with this disease during pregnancy some improvement in the functional abnormality might be expected from the physiological hypervolaemia which occurs. On the other hand, this potential benefit might be counteracted by the early increase in cardiac output (Walters et al., 1966). This increase in output is associated with a fall in peripheral vascular resistance but little change in mean blood pressure (Lees et al., 1967). Consequently the increase in left ventricular work is most pronounced in conditions with proximal left ventricular outflow obstruction such as aortic stenosis and hypertrophic obstructive cardiomyopathy. In addition, an actual increase in the severity of the labile obstruction accompanies any decrease in peripheral vascular resistance with the latter condition.

Because they produce inadequate left ventricular filling, lower the left ventricular end systolic volume, and reduce the forward output the following circumstances may be dangerous to the patient with hypertrophic obstructive cardiomyopathy and are particularly relevant to delivery: (1) interruption of venous return as occurs during the Valsalva manœuvre or violent expulsive effort, fainting, inhalation of amyl nitrite, or the administration of ganglion-blocking drugs; and (2) hypovolaemia due to acute blood loss.

Any increase in the contractile force of the heart may provoke or magnify the obstruction. Such an increase may be brought about by (1) physical exercise, emotional stress, pain, or anger, or by (2) inotropic drugs such as digitalis and adrenaline.

Conversely, hypervolaemia, peripheral vasoconstriction, and the squatting or supine positions all tend to distend the left ventricle and to reduce the obstruction. Because they reverse the effect of circulating adrenaline, beta-adrenergic blocking drugs such as propranolol may be beneficial (Cherian et al., 1966).

These theoretical considerations guided us in the management of the patients whose case histories (see Table) we report. We were, of course, especially influenced, firstly, by the increased sympathetic activity which accompanies the emotional and physical effort of labour; secondly, by the similarity of the normal second stage to a protracted series of Valsalva manœuvres; and, lastly, by the frequency of acute blood loss during pregnancy and delivery.

\section{Case 1}

The patient was one of five affected siblings. The disease was diagnosed at Hammersmith in 1956 after the sudden death of a brother and sister. 


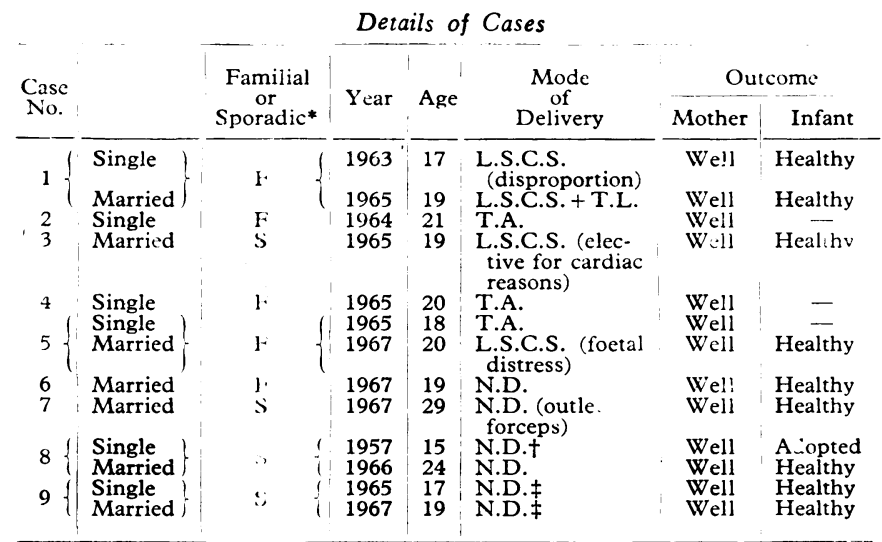

* Type of hypertrophic obstructive cardiomyopathy, whether familial or apparently sporadic type.

Delivered elsewhere in 1957, when her heart disease was undiagnosed. F Her first baby was delivered elsewhere before her heart disease was discovered. During her second pregnancy she was seen by us but was delivered elsewhere.
L.S.C.S. $=$ Lower segment caesarean section. T.L. $=$ Tubal ligation. T.A. $=$ Therapeutic abortion. N.D. = Normal delivery.

First Pregnancy, 1963.-An unmarried girl aged 17 was first seen at 24 4/7 weeks' gestation and was immediately admitted for observation. She was asymptomatic though anaemic ( $\mathrm{Hb} 9.4 \mathrm{~g}$./ $100 \mathrm{ml}$.) and the abnormal cardiac signs were basically unchanged from before pregnancy though possibly a little more exaggerated. She had jerky arterial pulses, a $6 \mathrm{~cm}$. dominant venous $a$ wave in the neck, a presystolic apical murmur, a short midsystolic ejection murmur, and a widely split second sound. (Similar signs had previously given rise to the erroneous diagnosis of mitral stenosis in one of the dead siblings.) The anaemia responded to parenteral iron therapy and she remained in hospital until 38 weeks, when an elective lower segment caesarean section was done, not only for the theoretical reasons that we have outlined above but also because of the presence of a major degree of cephalopelvic disproportion. Blood was cross-matched and available at the time of operation, but transfusion was not required. Ergometrine $0.5 \mathrm{mg}$. was given intravenously immediately after delivery. The infant was a live male weighing $2,860 \mathrm{~g}$. and there were no postoperative complications. The child was well and showed no signs of heart disease at the age of $4 \frac{1}{2}$ years.

Second Pregnancy, 1965.-The patient was now married. She had remained well between pregnancies and was still asymptomatic despite florid signs of hypertrophic obstructive cardiomyopathy. In view of our increased experience of the condition as a complication of pregnancy she was not admitted until 30 weeks, when she developed a respiratory infection which required treatment, and again at 34 weeks, when she had developed dyspnoea and tachycardia which responded to rest, sedation, and propranolol. A repeat elective lower segment caesarean section was carried out at 38 weeks, combined with tubal ligation. Once again blood was available but not required, and intravenous ergometrine was given after delivery of the child. Postoperative progress was uneventful, and the child, a boy, seemed to have a normal heart when examined at the age of 2 years.

Comment.-This patient may have inherited her cardiac disease from both parents, as her father died suddenly of a "heart attack" at 42 years and her mother also has heart disease, but as she has in addition an autoimmune haemolytic anaemia, her heart condition has not been fully investigated. The surviving sister is Case 6 in this series, and their surviving brother had been operated on for the relief of hypertrophic obstructive cardiomyopathy at Hammersmith. The pattern of hypertrophic obstructive cardiomyopathy was similar in all members of the family. Gross hypertrophy impeded ventricular filling but outflow gradients were a lesser feature. It has been our experience that sudden death is more common in this "pseudomitral stenosis" variety of hypertrophic obstructive cardiomyopathy than in the "pseudoaortic stenosis" type, and that the former type is more often familial while the latter type tends to be sporadic. ' Nevertheless, this patient had two successful pregnancies and remained well at the time of writing. In retrospect it may seem that our decision to undertake tubal ligation at the time of the second caesarean section was some- what light-hearted; but none the less, in view of our then limited experience of hypertrophic obstructive cardiomyopathy as a complication of pregnancy, as well as the theoretical risk of pregnancy and labour leading to sudden death, we felt that this young woman had been remarkably fortunate in producing two live infants after two uneventful pregnancies and deliveries.

\section{Case 2}

This patient was a spinster aged 19 when first seen at Hammersmith in 1961. Full haemodynamic studies and selective angiocardiography had already been carried out by Dr. I. R. Gray in Coventry, and she was referred for consideration of surgical relief of her left ventricular outflow obstruction. As this was severe and was associated with increasing incapacity from dizziness and angina provoked by effort, operation was advised and left ventriculomyotomy was performed by Professor H. H. Bentall on 13 February 1962. Progressive symptomatic improvement followed operation, and both clinical and postoperative haemodynamic and angiographic studies suggested alleviation of the functional abnormality. In June 1964 she complained of worsening of angina and increased dyspnoea in association with a pregnancy of 12 weeks' duration. In view of this deterioration and the still unknown hazard which pregnancy then entailed termination without sterilization was advised, Preoperatively she was placed on pronethalol (the original betaadrenergic blocking drug), and vaginal termination was carried out without complications. Cross-matched blood was available and intravenous ergometrine was used.

Following the termination her angina again improved and she was married in December 1964 . She has had no further pregnancies.

Comment.-The early exacerbation of angina in this patient might be explained by the early decrease in peripheral resistance outstripping the slower expansion of total blood volume and resulting in a net increase in outflow tract obstruction in the first trimester of pregnancy. It is possible that had the pregnancy been allowed to continue she might have shown later improvement.

\section{Case 3}

This patient, a married woman aged 19 , had been followed since 1945 , when ligation of a patent ductus had left her with a loud residual murmur. She had signs of outflow obstruction to both ventricles. There was no family history of heart disease. Though bilateral congenital subvalvular stenosis was seriously considered, catheterization demonstrated a labile obstruction and both the physical signs and the disproportionate ventricular hypertrophy seen on angiography were in accord with a diagnosis of hypertrophic obstructive cardiomyopathy. In 1965 she became pregnant and wished to marry and continue the pregnancy. She had effort dyspnoea before pregnancy and at 23 weeks developed pulmonary venous congestion which necessitated bed rest, pronethalol, and diuretics. She responded well to this treatment but was kept in hospital prophylactically.

At 37 weeks she went into spontaneous labour, and because of the views we then held on the undesirability of vaginal delivery in the presence of this heart condition an elective caesarean section was carried out and a live female infant delivered. There were no complications, and no deterioration in her cardiac state followed the pregnancy; but in 1967 she developed a Guillain-Barré the pregnancy whecessitated treatment on a respirator and unforsyndrome which necessitated a complication of this condition. The heart was sent to us through the kindness of Dr. F. E. T. Scott. Besides wisproportionate and asymmetrical hypertrophy of both ventricles with massive involvement of the interventricular septum it showed a membranous type of discrete subaortic stenosis due to abnormal insertion of an extension of the anterior mitral cusp below the aortic valve.

Comment.-This patient is considered to have had "secondary hypertrophic obstructive cardiomyopathy." We have now seen several examples of hypertrophic obstructive 
cardiomyopathy in association with mild or even severe organic obstruction to left ventricular ejection, but in her case the primary condition was missed by us because at the time we were unaware of their possible coexistence.

\section{Case 4}

This patient was a spinster aged 20. Her younger brother had died suddenly aged 12 with hypertrophic obstructive cardiomyopathy. She complained of syncopal attacks and increasingly severe angina when first seen in 1965 . At this time she was 11 weeks pregnant and was found to have florid signs of hypertrophic obstructive cardiomy pathy with obstruction mainly to left ventricular inflow. She had no intention of marrying, and on account of her severe symptoms, florid disease, and bad family history as well as her social circumstances the pregnancy was terminated by abdominal hysterotomy at 13 weeks' gestation. Operation was once again carried out after pronethalol therapy, and subsequent full haemodynamic and angiocardiographic study confirmed both the diagnosis and the severity of the condition.

\section{Case 5}

This girl's brother had died of gunshot wounds sustained during a game of Russian roulette. A coroner's necropsy revealed hypertrophic obstructive cardiomyopathy, though he had previously been thought to have rheumatic heart disease.

The patient was first seen by us in 1963, when she was 16 . She then had clear signs of hypertrophic obstructive cardiomyopathy. Haemodynamic and angiographic study confirmed this diagnosis and showed severe obstruction to left ventricular outflow, some inflow restriction, and mild mitral regurgitation. She was treated with pronethalol.

First Pregnancy.-In 1965 she reported when 12 weeks pregnant, saying that she had had no intention of getting married. Though she was asymptomatic it was felt that pregnancy was hazardous and that an unwanted pregnancy should be terminated. In view of the greater ease of controlling blood loss this was carried out by abdominal hysterotomy; there were no complications.

Second Pregnancy.-In 1967 she again reported with a 10-week pregnancy. She was asymptomatic and, being now married, was anxious to continue with the pregnancy. Since we had now gained confidence from experience with successful pregnancy in this disease the pregnancy was allowed to continue, She remained well and was taking propranolol $30 \mathrm{mg}$. t.d.s. She continued to do so throughout pregnancy, which was managed on an outpatient basis until 37 weeks, when she was admitted for rest. Vaginal delivery was planned, but foetal distress in the first stage necessitated an emergency lower segment caesarean section. The cord was tightly round the infant's neck, but the child, a girl, subsequently did well and appeared to be normal. There were no postoperative complications.

\section{Case 6}

This patient, a married woman aged 19, was the sister of Case 1. She was first seen in 1967 at 24 weeks' gestation in her first pregnancy. Her elder sister had already successfully had two children. Like her sister she had been known to us since 1956, when her heart disease was first recognized. Their cardiac signs were similar and they were both small and obese. A sinus tachycardia and a tendency to giddiness improved when she took propranolol, which was continued throughout the remainder of pregnancy in a dose of $30 \mathrm{mg}$. t.d.s. She was admitted at 34 weeks with a respiratory infection and again at 37 weeks for a rest. Earlier there had been some suggestion of cephalopelvic disproportion, but the head engaged by the 38th week and she was allowed to go into spontaneous labour. After a labour lasting only five and a half hours she was delivered by low forceps extraction with a pudendal block. During labour $20 \mathrm{mg}$. of propranolol was given intramuscularly, and she received $0.5 \mathrm{mg}$. of ergometrine intravenously with delivery of the anterior shoulder; cross-matched blood was available. Both child and mother have since done very well.

\section{Case 7}

A married State-registered nurse aged 29 was first seen by us in 1954, when hypertrophic obstructive cardiomyopathy with severe left ventricular outflow tract obstruction was diagnosed. An open ventriculomyotomy had been carried out on 18 July 1962 by Professor H. H. Bentall. Apart from a postcardiotomy syndrome she subsequently did well and improved symptomatically, though postoperative haemodynamic study showed that she still had a high left atrial pressure. Pregnancy was at first discouraged, but our initial good experiences suggested it would be reasonable to let her attempt this. She became pregnant in 1967, and remained on propranolol after the first eight weeks. During pregnancy she became a little more dyspnoeic and developed bronchitis, which was associated with definite evidence of pulmonary venous congestion. This responded to rest, antibiotics, and diuretics. Caesarean section was planned on account of the high left atrial pressure, but she went into spontaneous labour at 38 weeks. The first stage lasted only two hours and 40 minutes and she was delivered by forceps after 18 minutes in the second stage. Propranolol $20 \mathrm{mg}$. was given intramuscularly, cross-matched blood was available, and ergometrine $0.5 \mathrm{mg}$. was given intravenously with the delivery of the anterior shoulder.

Comment.-This patient with no family history of the condition had severe hypertrophy with residual inflow restriction following the operation for relief of outflow obstruction in 1962. Though she did well during pregnancy her resting left atrial pressure was high and clearly became higher from the hypervolaemia and increased cardiac output during pregnancy.

\section{Case 8}

This patient, a married woman aged 24 , was first seen by us in 1966 with a diagnosis of mitral stenosis and recurrent fainting attacks at 24 weeks. This was her second pregnancy, the first having occurred in 1957 at the age of 15 . During the pregnancy a heart murmur had been heard but had not been thought to be significant, and she had apparently had no difficulties in pregnancy or during delivery; the child was liveborn and had been adopted. There was no history of rheumatic fever and no known family history of heart disease. When we first saw her in her second pregnancy the signs were those of non-rheumatic mitral regurgitation. She was much troubled by dizziness on effort, but testing did not elicit change in either pulse or blood pressure. She was managed throughout pregnancy and delivery as a patient with mitral regurgitation and had a spontaneous vaginal delivery of a healthy female infant. Subsequent cardiac investigations showed that there was moderate mitral regurgitation associated with hypertrophic obstructive cardiomyopathy and mild left ventricular outflow obstruction.

Comment.-The incomplete diagnosis of this patient's cardiac condition during pregnancy and the uneventful course of pregnancy and delivery in the patient and in Case 9 played a great part in altering our attitude to the management of these patients during pregnancy and labour.

\section{Case 9}

In 1965 this patient, an unmarried girl aged 17, was first seen at Hammersmith shortly after an uneventful spontaneous delivery of a healthy infant because a heart murmur had been heard during pregnancy. The pregnancy itself had also been quite uneventful. There was no family history of heart disease but she had clear evidence of hypertrophic obstructive cardiomyopathy with mitral regurgitation and moderate outflow obstruction. This was confirmed by haemodynamic and angiographic study. She complained of intermittent dyspnoea and was started on propranolol with some subjective benefit. In 1967 she married and at the age of 19 once again became pregnant. Her obstetrical care was not undertaken at Hammersmith as she lived too far away, but we are grateful to Mr. S. S. F. Pooley for the information that this pregnancy was quite uneventful and ended in a normal spontaneous delivery of a healthy child. She took propranolol through the pregnancy and it was administered intramuscularly during labour. 


\section{Discussion}

Our experiences with these patients seem to have provided a neat example of the frequent contrast between theoretical considerations and practical obstetrics. As we have said, at first we were so apprehensive of the possible catastrophic effect of tachycardia, uncontrolled blood loss, or expulsive effort that after much consideration we chose elective caesarean section as being by far the safest method of delivery. It was our experience with Case 8 , who had a quite uneventful vaginal delivery at a time when her heart condition was thought to be nonrheumatic mitral regurgitation unassociated with hypertrophic obstructive cardiomyopathy, that led us to contemplate the feasibility and safety of normal delivery in these patients. In reaching this decision we gained comfort from the availability and apparent beneficial therapeutic effect of the beta-adrenergic blocking drugs. Eight of our patients took these drugs (pronethalol in three and propranolol in five) throughout pregnancy and during delivery without apparent effect on the foetus.

It is now our practice to undertake elective caesarean section only on the usual obstetrical indications as applicable to patients with cardiac disease. There is, for instance, no place for a prolonged trial of labour in these patients. During labour the patient is protected from the cardiac stimulant effects of pain, apprehension, and effort by intramuscular propranolol. Our present regimen is to give propranolol $20 \mathrm{mg}$. intramuscularly at the onset of labour followed by $15 \mathrm{mg}$. intramuscularly fourhourly until delivery is complete. An intravenous dextrose infusion is set up and blood cross-matched so that any loss may be replaced at once. The tendency to postural syncope which occurs in the later months of normal pregnancy through intermittent obstruction to the inferior vena cava could also be dangerous in hypertrophic obstructive cardiomyopathy and, during the first stage at any rate, these patients should not lie on their backs. As is our usual practice in patients with cardiac disease the second stage is curtailed, but in patients with hypertrophic obstructive cardiomyopathy this practice is more vital than with commoner forms of heart disease in view of the increase in obstruction that occurs during expulsive efforts. We do not wish to enter into the controversy as to whether ergometrine should be given at the end of the second stage to cardiac patients, but wish to state quite emphatically that in patients with hypertrophic obstructive cardiomyopathy its effects can only be beneficial. Not only is blood loss especially dangerous to these patients, but the peripheral vasoconstriction and possible increased right-sided filling caused by its use will tend to diminish the obstruction.

As these patients are at risk from infective endocarditis (Linhart and Taylor, 1966 ; Vecht and Oakley, 1968), penicillin and streptomycin cover should be begun at the onset of labour and continued for five days.

Our experience of pregnancy and labour has so far been so encouraging that we wondered whether this might not be fortuitous in such a small number of patients, as presumably is the high incidence of illegitimate pregnancies. Reviewing all our patients who had hypertrophic obstructive cardiomyopathy, we found no record of obstetrical disaster in their relatives, though such retrospective information is notoriously unreliable. Our 34 female patients who are at or beyond child-bearing age had 27 safe deliveries while unencumbered by the correct diagnosis of their cardiac disorder. So far as we could ascertain none of these pregnancies or deliveries had been complicated by sudden collapse or any other emergencies.

During the years 1957 to 1963 inclusive a total of 2,154 maternal deaths were reported to the Chief Medical Officer of Health for the purposes of the Confidential Inquiries into Maternal deaths. Of these, 1,545 were thought to be due to pregnancy and childbirth and 609 as deaths not classed to pregnancy or childbirth but associated therewith. Through the courtesy of Dr. Margaret Bates we have had the opportunity of seeing abstracts taken from the reports of all women during this period who had died suddenly during pregnancy and labour, in whom necropsy had revealed cardiac hypertrophy, but who were not known to be grossly hypertensive. We have only three abstracts in which the history and pathological findings suggest a possible diagnosis of hypertrophic cardiomyopathy.

On balance it would therefore seem that, despite the enormous theoretical hazards, these patients are not the quite extraordinary high-risk group that we had expected. None the less, the theoretical dangers are such that pregnancy must be followed by both physician and obstetrician with the greatest possible care, and we suggest that the precautions we have outlined should be adopted.

We wish to acknowledge gratefully all those physicians who have kindly referred patients and so allowed us to accumulate the experience recounted in the paper. We thank Professor J. F. Goodwin for permission to publish details of those patients who were under his care, and for much discussion and advice, and Professor J. C. McClure Browne and Mr. W. G. MacGregor for referring to us those patients who had come under their obstetrical care. We are grateful to Dr. Margaret Bates for her work in scanning the confidential inquiries.

Requests for reprints should be addressed to H. G. Dixon, Department of Obstetrics and Gynaecology, University of Bristol, Southmead Hospital, Westbury-on-Trym, Bristol.

\section{REFERENCES}

Braunwald, E., Lambrew, C. T., Morrow, A. G., Pierce, G. E., Rockoff, S. D., and Ross, J. (1964).' Circulation, 30, Suppl. No. 4.

Burchell, H. B. (1966). Circulation, 34, 556.

Cherian, G., Brockington, I. F., Shab, P. M., Oakley, C. M., and Goodwin, J. F. (1966). Brit. med. ł., 1, 895.

Cohen, J., Effat, H., Goodwin, J. F., Oakley, C. M., and Steiner, R. E. (1964). Brit. Heart 尹., 26, 16.

Cutforth, R., and MacDonald, C. B. (1966). Amer. Heart F., 71, 741.

Lees, M. M., Taylor, S. H., Scott, D. B., and Kerr, M. G. (1967). 7. Obstet. Gynaec. Brit. Cwlth, 74, 319.

Linhart, J. W., and Taylor, W. J. (1966). Circulation, 34, 595.

Rackley, C. E., Whalen, R. E., and McIntosh, H. D. (1966). Circulation, 34, 579.

Ross, J. Braunwald, E., Galt, J. H., Mason, D. T., and Morrow, A. G. (1966). Circulation, 34, 558.

Vecht, R. J., and Oakley, C. M. (1968). Brit. med. F., 2, 455.

Walters, W. A. W., MacGregor, W. G., and Hills, M. (1966). Clin. Sci., 30, 1 . 